\title{
El Proyecto Genoma Humano: Aspectos Éticos
}

José Hernández Yago

Arbor CLXII, 638 (Febrero 1999), 287-301 pp.

Todo conocimiento científico es positivo en cuanto que su contenido incrementa el control de la realidad. El desciframiento del genoma humano, con la consiguiente identificación y localización de los 50.000 a 100.000 genes que configuran su patrimonio genético, permitirá el progresivo esclarecimiento de los mecanismos reguladores de la expresión génica y pondrá al alcance del hombre posibilidades espléndidas, que requerirá años desentrañar. El acelerado ritmo en la caracterización de nuevos genes está desencadenando la posibilidad de pronosticar un número cada vez mayor de enfermedades genéticas $y$, por tanto, puede propiciar la práctica de una Medicina preventiva cada vez más rigurosa.

Sin embargo, las posibles aplicaciones del conocimiento científico que aporta este proyecto suscitan también importantes inquietudes, desde el momento en que cada ser humano puede convertirse en un ser sin intimidad biológica. Por otra parte, la Tecnología del ADN recombinante, al tiempo que aporta la enorme posibilidad de una futura terapia génica, suscita también legítimas preocupaciones sobre el correcto uso de estos conocimientos.

En este artículo se abordan algunas de las cuestiones de carácter ético que ya plantea actualmente el Proyecto del Genoma Humano. Se adopta la perspectiva según la cual el respeto al patrimonio genético debería estar siempre presidido por un principio básico: no perder nunca de vista al hombre, esto es, al ser humano y su derecho a la identidad personal propia. 


\section{Introducción}

Todos seres vivos estamos formados por células, que son a la vez unidades estructurales y funcionales. Entre esos seres, hay algunos que están formados por una sola célula (las bacterias, por ejemplo); mientras que otros, como el ser humano, comienzan siendo una sola célula -el zigoto, o célula resultante de la unión de un espermatozoide y de un óvulo-, que rápidamente se divide en dos, y cada una de éstas, a su vez, en otras dos hasta llegar en la persona adulta a unas $10^{13}$ células. Juntas trabajan coordinadamente en lo que, con toda propiedad, llamamos «organismo".

Las células de nuestro organismo - como es el caso de todos los llamados eucariotas-, en el compartimento del núcleo, contienen un manual de instrucciones donde se especifican sus distintas funciones. Aunque ese manual es el mismo para todas las células de un mismo organismo, cada estirpe celular - neuronas, epidérmicas, musculares, etc.- usa capítulos diferentes del mismo para cumplir su propia función. El manual contiene, asimismo, la información en cuya virtud el zigoto emprende, sin solución de continuidad, su desarrollo hasta llegar a ser adulto y, además, sigue suministrando información mientras el individuo madura física e intelectualmente.

El manual difiere de un sujeto a otro, de suerte que en él están especificadas casi todas las características físicas y muchas de las claves del comportamiento que nos individualizan. El manual consta de unas 100.000 instrucciones (en dos versiones: una heredada de la madre y otra, del padre) cada una de las cuales es responsable de una característica o función diferente en nuestro organismo. Manual tan extraordinario se llama "genoma" y cada una de esas instrucciones es un gen.

Los genes son como segmentos de una macromolécula, el ácido desoxirribonucleico (ADN), que, como es bien sabido, es un polímero formado por cuatro estructuras químicas bastante semejantes, los $\mathrm{nu}$ cleótidos, que difieren entre sí por las "bases" que entran a formar parte de los mismos. Las bases son adenina (A), citosina (C), guanina (G) y timina (T). Los nucleótidos se encuentran unidos linealmente formando una secuencia, aparentemente al azar.

Hay que decir que esta molécula lineal va acompañada por otra de la misma naturaleza, que le es complementaria, formando con la primera un dúplex (una doble cadena de estructura helicoidal) donde la A de una de las moléculas se empareja siempre con la $\mathrm{T}$ de la molécula complementaria y viceversa. Esto mismo ocurre entre la G 
El Proyecto Genoma Humano: Aspectos Eticos

y la C. Esta estructura en doble hélice con pares de bases complementarias, resulta tremendamente útil para que puedan producirse copias fidedignas de la molécula original (replicación) al tener que dividirse las células. En cada división celular se replica el manual entero: una copia para cada célula resultante.

El genoma humano consta de unos tres mil millones de pares de nucleótidos. La cantidad de este ADN que codifica los 100.000 genes representa sólo un 5-10\% del total del genoma; el resto corresponde a secuencias tales como intrones, secuencias intergénicas, pseudogenes, y elementos repetitivos cuya importancia y funciones están siendo estudiadas.

Cuando la célula se divide, el ADN se pliega formando unos ovillos muy característicos - los cromosomas- que pueden verse bien con la ayuda de un microscopio ordinario. Cada célula humana tiene 46 cromosomas distribuidos en 23 pares. Un cromosoma de cada par se hereda del padre y el otro, de la madre.

\section{Algunos descubrimientos relevantes}

Si tuviéramos que enumerar los descubrimientos clave, en las últimas décadas, que han permitido el desarrollo de la Ingeniería Genética y el planteamiento del Proyecto del Genoma Humano, no deberíamos omitir los siguientes:

- En 1953, Watson y Crick desvelan al mundo, en un artículo de una sola página en la revista Nature, la estructura en doble hélice del ADN (1).

- En 1961, Schildkraut, Marmur y Doty (2) descubren el fenómeno de la renaturalización del $\mathrm{ADN}$, confirmando el modelo propuesto por Watson y Crick, que pone de relieve la posibilidad de hibridación entre cadenas simples de ADN que sean complementarias. El proceso de renaturalización del ADN consiste en que, si separamos las dos cadenas de una doble hélice - fenómeno denominado desnaturalización, que se produce elevando la temperatura o el ph- y después restauramos las condiciones iniciales, ambas cadenas vuelven a reconstruir la doble hélice.

- En 1962, Dussoix y Arber (3) ponen en evidencia, por primera vez, la existencia en bacterias de endonucleasas de restricción, enzimas que reconocen secuencias específicas de nucleótidos en la doble hélice de ADN y la cortan a ese nivel. Se conocen varias decenas de estos enzimas, cada uno reconociendo secuencias diferentes de nucleótidos. 
El uso de estos enzimas hace posible en la actualidad determinar inequívocamente la identidad de una persona a partir de una muestra reducida de sus células, puesto que los fragmentos de $\mathrm{ADN}$ que se obtienen tras su tratamiento con un conjunto de este tipo de endonucleasas presentan unos tamaños característicos de cada individuo, en función de la propia secuencia de nucleótidos, su ADN; y la ordenación de dichos fragmentos, de acuerdo con su longitud, mediante electroforesis ("mapa de restricción") viene a ser como un código de barras específico de dicho individuo. El interés que esta técnica ha despertado en medios judiciales es enorme, máxime si se considera que actualmente se puede multiplicar la cantidad de ADN presente en unas pocas células (la técnica PCR, iniciales de polymerase chain reaction).

- En 1966, gracias a los estudios de los grupos de Nirenberg (4), Ochoa (5) y Khorana (6), se completa el desciframiento del código genético, en una carrera apasionante de investigaciones que fueron posibles gracias al descubrimiento por el grupo de Ochoa, en 1955 (7), de la polinucleótido fosforilasa. Este enzima, que cataliza la síntesis de ARN a partir de nucleótidos simples, fue precisamente la "piedra Rosetta" - en palabras de Severo Ochoa (8)- que permitió el deciframiento del código genético.

La información genética contenida en el ADN se transmite al sistema celular de síntesis de proteínas de modo que una cierta secuencia de nucleótidos del ADN dirige la formación de una proteína con una secuencia única de aminoácidos. El mecanismo por el cual se transmite esa información es el siguiente: cada secuencia de 3 nucleótidos contiguos en el ADN especifica un aminoácido concreto. De este modo, la información contenida en el ADN es más que suficiente para especificar 20 aminoácidos, ya que el número de permutaciones de cuatro nucleótidos distintos, tomados de 3 en 3 , asciende a 64 , mientras que el número de aminoácidos es sólo de 20.

- En 1967, el grupo de Gellert (9) descubre el enzima ADN-ligasa que permite soldar fragmentos de $\mathrm{ADN}$, dando paso a la posibilidad de construir ADN recombinante.

- En 1972-73, los grupos de Boyer (10), Cohen (11) y Berg (12) desarrollan las técnicas de clonado de ADN.

- En 1975-77, tanto el grupo de Sanger (13 y 14) como Maxam y Gilbert (15) desarrollan métodos de secuenciación rápida del ADN.

Con todos los descubrimientos reseñados tenemos los medios precisos para abordar proyectos interesantísimos de Ingeniería Genética y también el "Proyecto Genoma Humano", cuyo objetivo es ubicar los aproximadamente 100.000 genes que poseemos en los diferentes cromosomas, 


\section{El Proyecto Genoma Humano: Aspectos Eticos}

y determinar cuál es la secuencia de los 3.000 millones de pares de nucleótidos que componen todo el ADN del ser humano.

\section{Orígenes del Proyecto Genoma Humano}

El Proyecto parece haber tenido varios orígenes. Uno de ellos se remonta a un meeting celebrado en Alta (Utha, USA) en 1984, cuando un grupo de científicos (entre ellos Ray White y Mortimer Mendelsohn), reunidos bajo los auspicios del Departamento de Energía de los Estados Unidos, con el fin de desarrollar métodos que permitieran detectar niveles de mutaciones producidas por exposición a radiaciones de baja energía y agentes ambientales, llegaron a la siguiente conclusión: lograr su objetivo (esto es, ser capaces de detectar una base alterada en el ADN de entre $10^{8}$ ) suponía casi tanto trabajo como secuenciar el genoma completo (16).

Otros orígenes significativos incluyen un meeting organizado por Robert Sinsheimer en Santa Cruz, en 1985, y un artículo de Renato Dulbecco, en 1986, publicado en Science (17). Todas estas raíces parecen converger, por primera vez, en 1986 en Cold Spring Harbor, que es cuando cristaliza el modelo actual del Proyecto, que se presenta como resultado de un esfuerzo cooperativo multinacional implicando a un amplio conjunto de centros de investigación.

En Octubre de 1988 se celebra en Valencia el primer Workshop on International Cooperation for the Human Genome Project, al que asisten unos doscientos científicos de diferentes países incluyendo varios galardonadaos con el Nobel: Ochoa, Anfinsen, Smith y Dausset. De esta reunión surge lo que ha dado en llamarse la «Declaración de Valencia" (18).

Sin ningún género de dudas, el conocimiento del genoma -como todo conocimiento científico- es positivo en cuanto que incrementa el control sobre la realidad. Así, con esa información se podrá dar un paso de gigante desde un punto de vista médico, pues potencia la posibilidad de una Medicina "predictiva" (19), en cuanto que podrá pronosticarse la existencia de patologías congénitas y los riesgos que hay de adquirir ciertos tipos de enfermedades. A este respecto, ya se poseen pruebas empíricas suficientes que señalan que hay predisposiciones genéticas para bastantes tipos de cáncer, diabetes, ciertas enfermedades mentales, etc.

Sin embargo, el planteamiento del Proyecto ha suscitado también interrogantes en cuanto al uso de la información. Porque el simple 
conocimiento del genoma de una persona puede comportar evidentes implicaciones con consecuencias negativas: problemas en el mercado de trabajo al ser puesta en evidencia - en un informe pedido por la empresa - alguna tara genética que hace predecible una mayor susceptibilidad a un determinado tipo de enfermedad o una esperanza mayor o menor de vida; problemas derivados de un mayor control sobre la persona por parte del Estado ...; problemas si las compañías de seguros piden el informe genético de los clientes. El ser humano corre el peligro de convertirse en un ser de cristal, sin intimidad biológica. Por otra parte, la Tecnología del ADN recombinante proporciona a los científicos la capacidad de insertar ADN de un organismo (o simplemente ADN "sintetizado" en el laboratorio) a otro organismo, lo que suscita legítimas preocupaciones sobre el correcto uso de estos conocimientos.

De hecho, Valencia volvió a ser - esta vez, en 1990 - la sede de un nuevo Workshop (20), que congregó a un centenar de participantes y que trató exclusivamente de los aspectos éticos de algunas de la posibles aplicaciones de los resultados del Proyecto. Entre los participantes figuran una extensa relación de científicos, que incluía a varios Premios Nobel -Watson (entonces Director del Proyecto Genoma Humano en USA), Dausset y Gilbert-; a expertos en Ética; a representantes de diversos Gobiernos de países interesados en el desarrollo del Proyecto; y personal de Organismos Internacionales -C.E.E. y UNESCO-, así como representaciones de diversas confesiones religiosas.

\section{Aspectos éticos del Proyecto Genoma Humano}

Centrándonos en los aspectos éticos, habría que decir, para comenzar, que no han faltado voces que consideran que el desarrollo de este Proyecto irá en detrimento del fomento de otras investigaciones más prioritarias, más urgentes. Sin duda, se trata de un ejemplo que ilustra bien el problema ético que supone la elección de los objetivos a investigar y de los medios públicos, humanos y materiales que van a ponerse a disposición de este fin (21). En un artículo publicado en la revista TIBS (22) se afirma que "la cartografía del genoma y los proyectos de secuenciación son inapropiados y malgastan preciosos fondos que deberían ir a investigación. Orientados a descifrar secuencias de nucleótidos, los Proyectos del genoma resaltan los productos de la Ciencia, no el proceso de la Ciencia. Es dudoso que la mayor parte de la in- 
El Proyecto Genoma Humano: Aspectos Eticos

formación que se consiga aporte nuevas luces sobre enfermedades humanas o procesos biológicos fundamentales. La naturaleza rutinaria de la secuenciación del genoma hace inadecuada esta labor para la formación de jóvenes científicos. Proyectos así pueden también impedir la educación de futuros investigadores al desviar fondos para investigación desde las Universidades hacia los centros y firmas comerciales implicados en dicho Proyecto".

Apuntamos sucintamente, a continuación, algunas otras cuestiones de carácter ético - entre las muchas posibles- que el conocimiento del genoma humano está ya planteando (para mayor detalle sobre el tema pueden verse las referencias bibliográficas 20,23 y 24).

La investigación sobre el genoma humano va a permitir predecir la probabilidad de adquirir una enfermedad $-\mathrm{y}$, en algunos casos, la certeza de llegar a tenerla - años o décadas antes de poder disponer de un tratamiento eficaz. A título de ejemplo: la enfermedad de Huntington es una enfermedad hereditaria - cuyo gen defectuoso es dominante ${ }^{1}-$, y sus primeros síntomas suelen aparecer entre los $30 \mathrm{y}$ 40 años, es decir, después de que las personas afectadas han podido tener hijos. La enfermedad es progresiva, con movimientos incontrolados y de demencia, e invariablemente fatal. El gen ha sido identificado, $\mathrm{y}$ esto permite hacer un test presintomático y diagnosticar si se es portador del gen defectuoso. Tal posibilidad genera, sin duda, toda una dinámica psicológica no exenta de dificultades éticas, que van a plantearse en la diagnosis de predisposiciones genéticas a ciertas enfermedades. La experiencia ha demostrado que el proceso de explicar los riesgos genéticos es complejo; la comprensión del problema llega lenta y penosamente, las cargas psicológicas son tremendas y nadie quiere conocer su propio riesgo. Por otra parte, el uso de este tipo de análisis plantea, en muchos casos, problemas adicionales porque se basa en el estudio de muestras de ADN de parientes afectados y sanos de la persona que se desea diagnosticar, lo que supone obtener información acerca de los riesgos de otros miembros de la familia, los cuales pueden no desear conocer su propio status y, al no participar, pueden conducir a conflictos familiares.

Pero existen, además, otros intereses en juego, aquellos en los que el conocimiento genético de los individuos es requerido por ciertas organizaciones. Consideremos el uso de pruebas genéticas antes de contratar a una persona, con el fin de revelar una predisposición genética que suponga para el individuo un mayor riesgo de adquirir un determinado tipo de enfermedad asociado a las circunstancias del trabajo que va a desarrollar. Cabría considerar dos supuestos para la prueba: 
que sea voluntaria o que se haga obligatoria. El primer supuesto no plantea un problema ético, en cuanto que las personas que solicitan el empleo deberían ser las primeras interesadas en conocer dicho riesgo y decidir si aceptan o no el puesto de trabajo. Sin embargo, la prueba genética obligatoria dirigida a la posible exclusión de las personas afectadas por una determinada predisposición genética presenta nuevos matices: se puede violar la autonomía del individuo y, además, la información obtenida podría utilizarse de un modo inadecuado. Por ejemplo, una prueba genética para la "anemia falciforme", seguida de la exclusión de aquellos individuos que, aunque sanos, sean portadores del gen causante de la enfermedad supondría excluir a uno de cada ocho candidatos de color en Estados Unidos ${ }^{2}$. Por otra parte, en aquellos lugares con abundancia de mano de obra, este tipo de prueba conduciría a las empresas a eliminar a los individuos susceptibles, más que a invertir en nuevos equipamientos que disminuyeran la exposición a los factores nocivos para la salud. La perspectiva de tales efectos indeseables, junto con el respeto debido a la libertad de la persona, hace de este tipo de pruebas obligatorias una cuestión éticamente problemática.

Más importante aún, desde el punto de vista ético, resulta el uso de la información genética para rechazar a aquellas personas que solicitan un trabajo por su propensión a determinadas enfermedades comunes, no relacionadas con el trabajo a realizar (infarto, depresiones, enfermedades mentales, cáncer...). Tales individuos pueden verse relegados no sólo a un desempleo temporal sino a un desempleo definitivo.

Por su parte, las compañías de seguros han empezado a considerar su postura acerca de las pruebas genéticas de sus futuros asegurados, conscientes de que, cuando estas pruebas estén al alcance de la práctica médica, los individuos pueden ser analizados privadamente para conocer si tienen especiales riesgos a contraer ciertas enfermedades y, si ese es el caso, se dirigirán con mayor probabilidad que los demás a las compañías de seguros para firmar una póliza por la mayor cantidad de dinero que les sea posible.

Otro punto de reflexión sobre las implicaciones éticas y legales que se derivarán del conocimiento del genoma humano se refiere al hecho de que el desarrollo de este Proyecto acentuará, sin duda, la tendencia a dar explicaciones genéticas a las diferencias entre individuos y/o grupos sociales, étnicos, etc., por dos vías diferentes. En primer lugar, las investigaciones sugerirán que las diferencias genéticas se correlacionan con una amplia variedad de comportamientos, con la tentación subsiguiente de dar una explicación a estos últimos esen- 


\section{El Proyecto Genoma Humano: Aspectos Eticos}

cialmente genética y, por consiguiente, eludir la responsabilidad del individuo. En segundo lugar, en la acometida inicial de hallazgos de posibles conexiones entre la genética del individuo y su comportamiento, se puede llegar a exageraciones a la hora de aceptar explicaciones genéticas para un amplio rango de fenómenos desde enfermedades mentales, enfermedades de adicción o debidas al medio ambiente, hasta discapacidades para la adquisición de conocimientos de diferentes grupos raciales o sociales.

Otro aspecto de primordial importancia ética es el diagnóstico genético prenatal, con todo lo que supone la posibilidad de que el simple conocimiento de que un feto esté afectado o sea portador de una enfermedad genética pueda convertirse en causa de aborto. El riesgo de una aplicación eugenésica de estos conocimientos es evidente. En no pocos científicos se detectan posiciones de carácter sociológico de esa índole, que recuerdan las ideas eugenistas que se situaban en la vanguardia de los ambientes intelectuales en la primera mitad de siglo y que defendían "científicamente" propuestas tales como el evitar la mezcla de las razas humanas superiores con las inferiores; el considerar enemigos del Estado a los ciudadanos más mediocres; construir una aristocracia biológica hereditaria; o el crear centros eutanásicos para los delincuentes peligrosos o para esterilizar a los inútiles. La historia de Carrie Buck, expuesta en el Segundo Workshop Internacional sobre el Proyecto Genoma Humano: Ética (25) por el Prof. J. David Smith, del Departamento de Desarrollo Humano del Lyneburg College de Virginia, constituye un patético ejemplo de lo que acabamos de referir. Estimo de interés transcribir algunos fragmentos de su ponencia:

«En el año 1927 una joven llamada Carrie Buck fue esterilizada contra su voluntad. Fue la primera persona sometida a este tipo de cirugía al amparo de una ley de Virginia. Dicha ley permitía imponer la esterilización a personas diagnosticadas como incapacitadas y que, probablemente, podían transmitir a sus descendientes deficiencias físicas, psicológicas o sociales. Carrie Buck había sido recluida en una institución para personas diagnosticadas como "deficientes mentales". Tras el internamiento, dio a luz a una hija ilegítima (Vivian). La madre de Carrie había sido internada en la misma institución algunos años antes, aparentemente como resultado de la prostitución y de otras conductas socialmente inaceptables. Se informó de que la hija de Carrie mostraba también signos de deficiencia mental.

Para los médicos, abogados y políticos que deseaban que la ley de esterilización de Virginia fuera válida constitucionalmente, Carrie Buck parecia ser la persona ideal para poner a prueba dicha ley. El juicio 
de aquellos que seleccionaron a Carrie para el caso de la prueba demostró ser válido. El Tribunal Supremo apoyó la constitucionalidad de la ley en el caso que llegó a ser reconocido como Buck v. Bell. Al expresar la opinión de la mayoría respecto de la decisión, el magistrado Oliver Wendell Holmes escribió:

«Hemos visto en más de una ocasión que el bienestar público puede exigir el sacrificio de la vida de sus mejores ciudadanos. Sería extraño que no pudiera exigir a aquellos que ya socavan la fuerza del Estado menores sacrificios, percibidos con frecuencia como importantes por las personas afectadas, a fin de evitar que la incapacidad inunde nuestra existencia. Es mejor, para el conjunto del mundo, que en vez de tener que llegar a ejecutar a unos descendientes degenerados debido a sus acciones delictivas, o dejarles morir de hambre a causa de su imbecilidad, la Sociedad pueda impedir que aquellos que están manifiestamente incapacitados sigan propagando su propia especie. El principio que apoya la vacunación obligatoria es lo bastante amplio como para justificar la ablación de las trompas de Falopio...”.

La esterilización de Carrie Buck pasó a la Historia del Derecho y a los anales de las Ciencias Sociales. La saga de la eugenesia y del darwinismo social en Estados Unidos, y también en todo el mundo, no se puede simplemente mencionar sin hacer referencia a la decisión del Tribunal Supremo en dicho caso. El hecho de que la integridad legal de la esterilización obligatoria fuera aceptada por el máximo tribunal en un país que se enorgullecía de su compromiso con la libertad del individuo tuvo un gran impacto. Carrie, como protagonista del caso, se convirtió en una figura histórica de fama internacional. Carrie, como persona, vivió una vida marcada por lo que, de forma errónea, declararon y decidieron sobre ella personas con poder e influencia.

Al caso de Carrie le siguieron miles de casos de otras personas que fueron esterilizadas también al amparo de lo previsto por la ley. La ley de Virginia se convirtió también en el modelo para los estatutos de esterilización en otros Estados. Haciendo un cálculo moderado, unas 50.000 personas fueron esterilizadas en Estados Unidos conforme a lo dispuesto en estos estatutos. Hay que admitir que la ley de Virginia fue también el modelo utilizado como parte del programa nazi de higiene racial. El 14 de julio de 1933, la ley de esterilización, inspirada en el modelo del defensor de la eugenesia, Harry Laughlin, utilizado en Virginia, se convirtió en ley en Alemania.

Holmes, al expresar por escrito la opinión de la mayoría en el caso Buck v. Bell, utilizó una frase, ahora famosa: "tres generaciones de imbéciles son suficientes". Su razonamiento y lenguaje eran coherentes con la opinión eugenésica de que muchos de los rasgos socialmente 


\section{El Proyecto Genoma Humano: Aspectos Eticos}

indeseables, entre ellos el retraso mental, eran en gran parte hereditarios....

La evidencia eugenésica y las predicciones relacionadas con el caso de Carrie Buck demostraron ser enormemente inexactas. Vivian, la hija de Carrie, de la que se dijo que representaba "la tercera generación de imbéciles", creció convirtiéndose en una niña atractiva que fue una estudiante con una mención de honor. Carrie, acusada de ser la segunda generación de imbéciles, fue puesta en libertad condicional, después de haber sido esterilizada, y enviada a un pueblecito de montaña donde pronto contrajo matrimonio con el sheriff suplente. Allí llevó una vida modesta, pero productiva y respetable. Tras la muerte de su marido se trasladó a una población más grande en donde se ganó su sustento cuidando personas de edad avanzada y con enfermedades crónicas. Sus amigos y patronos dieron fe de que Carrie Buck no era una deficiente mental. En realidad, los especialistas en salud mental que la observaron posteriormente en su vida no encontraron evidencia de retraso mental”.

Se trata de una campo todavía en sus inicios, pero que ha sido motivo de importantes reflexiones éticas. La principal diferencia, éticamente significativa, entre terapia génica y cualquier otro tipo de terapia reside en el hecho de que el resultado de la terapia génica puede afectar a la progenie, mientras que las demás sólo afectan al individuo que la recibe. Esta consideración ha conducido a una distinción crucial a la hora de valorar éticamente la investigación de la terapia génica, según se trate de aplicarla a células somáticas o a células germinales. Sólo las alteraciones genéticas de las células germinales -óvulos y espermatozoides - pueden pasar a la progenie, mientras que los cambios genéticos en las células somáticas - todas las demásdesaparecerán con el individuo.

En este sentido, adoptadas las debidas precauciones que deben regir la experimentación en seres humanos, la terapia génica en células somáticas es éticamente análoga a los demás tipos de terapia. No ocurre lo mismo con la terapia génica aplicada a células germinales, cuyos efectos sobre el patrimonio genético de la descendencia plantean justamente una profunda preocupación.

El curso de las investigaciones permite aventurar que, en el próximo siglo, se pondrán en marcha ensayos clínicos de terapias génicas para un número muy amplio de enfermedades. Sin embargo, la terapia basada en la línea germinal no se contempla como opción en un futuro previsible, debido en parte a que los cambios producidos en el genoma, como consecuencia de su aplicación, se transmitirían de generación en generación, lo que plantea profundos problemas de naturaleza ética. Cabe 
mencionar algunos de esos problemas: ¿Se aplicaría la terapia para mejorar la raza, y no sólo para prevenir una enfermedad hereditaria? ¿A quién correspondería decidir sobre el particular? ¿Está dispuesta la Sociedad a afrontar el riesgo que supone introducir cambios en el patrimonio genético del género humano que podrían, en última instancia, ser deletéreos? ¿Tenemos derecho a inmiscuirnos en la evolución humana? La perspectiva de una terapia génica de las células somáticas es menos problemática, por la razón principal que sólo afecta al propio paciente.

Insistiendo en lo mismo, cito el último punto de las conclusiones del Workshop sobre el Proyecto Genoma Humano: Ética, celebrado en Valencia en 1990, ya mencionado anteriormente:

Estamos de acuerdo en que la terapia genética de las células somáticas puede ser utilizada para el tratamiento de enfermedades humanas especificas. La terapia genética de la línea germinal afronta numerosos obstáculos y no ofrece un consenso ético general. Nosotros apoyamos un mayor debate sobre las cuestiones técnicas, médicas y sociales de este tema.

Tras la lectura de estas Conclusiones, el Premio Nobel Profesor Dausset intervino para hacer patente su inquietud por la falta de contundencia de las mismas y no recoger aspectos que él había propuesto incluir. Lo que el Profesor Dausset dijo fue lo siguiente:

«Nuestra Civilización está basada en el respeto al ser humano. Este respeto nace del hecho de que cada individuo es único. Esta idea que antes era mera intuición, está ahora demostrada genéticamente. En el estado actual de nuestros conocimientos, nosotros somos probablemente incapaces de mejorar la maravilla del ser humano y de su mente prodigiosa, en cambio es muy fácil que lo deterioremos. Estoy de acuerdo en lo adecuado de un posible uso de una terapia genética de las células somáticas para el tratamiento de enfermedades humanas específicas, pero proponemos una moratoria en la aplicación de estas técnicas en células germinales y en el embrión. Y ello por dos razones:

1. Desconocemos cuál sería el resultado de tales experimentos.

2. Abriríamos la puerta a un uso erróneo de la Genética por parte de ideologías, especialmente ideologías totalitarias".

Subyace en estos temores y en estas reservas algo que está latente en este tipo de experimentación, que incide en lo que ha dado en llamarse la "molécula de la vida", el $\mathrm{ADN}$ : el respeto al patrimonio genético humano consiste, en primer lugar, en conocerlo. No hay respeto sin conocimiento. Y conocer el patrimonio genético significa desarrollar nuevas técnicas de diagnóstico, supone profundizar en los mecanismos 


\section{El Proyecto Genoma Humano: Aspectos Eticos}

que hacen realidad el mensaje genético heredado. El progresivo esclarecimiento de los mecanismos reguladores de la expresión génica pondrán al alcance del hombre posibilidades espléndidas; en segundo lugar, el respeto al patrimonio genético consiste en no perder nunca de vista al hombre, esto es, al ser humano y su derecho a la identidad personal propia.

\section{Conclusión}

La conclusión que cabe extraer de este trabajo coincide con una larga cita de la ponencia del Profesor J. David Smith (26), a la que se ha hecho referencia anteriormente, porque refleja adecuademente los aspectos éticos del Proyecto dedicado al estudio del Genoma Humano.

«El mayor reto planteado por el Proyecto del Genoma Humano radica en realizar su trabajo y aportar los beneficios de sus esfuerzos a un mundo de personas, cuyo ser es mucho más que la suma total de sus componentes biológicos. Para estar por encima de las tentaciones y de los peligros que encierra el determinismo biológico, debemos seguir considerando a las personas como agentes de libertad y de dignidad.

En mi opinión, debemos comprometernos, en primer lugar, con los derechos y valores básicos humanos. Y esto debe ser así, aunque la capacidad de intervenir convenientemente en las vidas de los demás nos parezca que es lo mejor para ellos y para la Sociedad, y aun cuando las "necesidades percibidas de nuestros tiempos" parezcan instarnos con apremio para actuar de forma rápida y eficaz.

El libre albedrío moral y ético es atributo de las personas, no de la Ciencia ni del método científico. Reconocer que somos agentes éticos y morales, y que las decisiones de que lo que debemos hacer, en contraposición con lo que podemos hacer, recaen sobre nosotros como personas, es un hecho que sobrecoge realmente. Por otra parte, es fascinante...».

\section{Notas}

1 Como ya se ha mencionado, en el genoma hay dos versiones de cada gen, una heredada del padre y otra de la madre. Aquella versión que utilizan las células se llama dominante y la otra, recesiva. En el caso que nos ocupa, la versión dominante es la defectuosa y, aunque la otra versión sea normal, el individuo estará afectado por la enfermedad. 
2 Considérese que, en este caso, la versión defectuosa de este gen es recesiva y, por lo tanto, si la otra versión del gen es normal, como esta versión es la dominante, el individuo está sano.

\section{Bibliografía}

1 Watson, J. D. y CRICK, F. H. C. (1953), "Molecular structure of nucleic acids: a structure for deoxyribose nucleic acid", Nature, v. 171, pp. 737-738.

2 Schildkraut, C. L., Marmur, J. y DOTY, P. (1961), "The formation of hybrid DNA molecules and their use in studies of DNA homologies", Journal of Molecular Biology, v. 3, pp. 595-617.

3 Dussorx, D. y ARBER, W. (1962), "Host specificity of DNA produced by Escherichia coli II. Control over acceptance of DNA from infecting phage lambda", Journal of Molecular Biology, v. 5, pp. 37-49.

4 NirenberG, M. W. y MATTAhei, J. H. (1961), "The dependence of cell-free protein synthesis in Escherichia coli upon naturally occuring or synthetic polyribonucleotides", Proceedings of the National Academy of Sciences, v. 47, pp. 1588-1602.

5 LENGYEL, P., SPEYER, J. F. y OCHOA, S. (1961), "Synthetic polynucleotides and the amino acid coden, Proceedings of the National Academy of Sciences, v. 47, pp. 1936-1942.

6 Nishimura, S., JonEs, D. S. y Khorana, H. G. (1965), "The in vitro synthesis of a copolypeptide containing two amino acids in alternating sequence dependent us $\mathrm{a}$ a DNA-like polymer containing two nucleotides in alternating sequence", Journal of Molecular Biology, v. 13, pp. 302-324.

7 GrunBerg-MANAGO, M. y OCHOA, S. (1955), “Enzymatic synthesis and breakdown of polynucleotides; polynucleotide phosphorylase", Journal of American Chemical So. ciety, v. 77, pp. 3165-3166.

8 OchOA, S., La emoción de descubrir, Conferencia impartida en Valencia el 5 de octubre de 1989 .

9 Zimmerman, S. B., Little, J. W., Oshinsky, C. K. y Gellert, M. (1967), «Enzymatic joining of DNA strands: a novel reaction of diphosphopyridine nucleotide", Proceedings of the National Academy of Sciences, v. 57, pp. 1841-1848.

10 Yoshimori, R., Roulland-Dussorx, D. y BOYER, H. W. (1972), «R factor-controlled restriction and modification of deoxyribonucleic acid: restriction mutants", Journal of Bacteriology, v. 112 , pp. $1275-79$.

11 COHEN, S. N., Chang, A. C. Y. y HsU, L. (1972), "Nonchromosomal antibiotic resistance in bacteria: genetic transformation of Escherichia coli by R-factor DNA", Proceedings of the National Academy of Sciences, v. 69, pp. 2110-2114.

12 Jackson, D. A., Symons, R. H. y BerG, P. (1972), "Biochemical method for inserting new genetic information into DNA of simian virus 40: circular SV40 DNA molecules containing lambda phage genes and the galactose operon of Escherichia coli", Proceedings of the National Academy of Sciences, v. 69, pp. 2904-2909.

13 SANGER, F. y COULSON, A. R. (1975), "A rapid method for determining sequences in DNA by primed synthesis with DNA polymerase", Journal of Molecular Biology, v. 94, n. 3 , pp. $441-448$. 


\section{El Proyecto Genoma Humano: Aspectos Eticos}

14 Sanger, F.; Air, G. M.; Barrell, B. G.; Brown, N. L.; Coulson, A. R.; Fiddes, C. A.; Hutchison, C. A.; Slocombe, P. M.; y SMith, M. (1977), "Nucleotide sequence of bacteriophage phi X174 DNA", Nature, v. 265, pp. 687-695.

15 MAXAM, A. M. y GilberT, W. (1977), "A new method for sequencing DNA", Proceedings of the National Academy of Sciences, v. 74, pp. 560-564.

16 CANTOR, C. R. (1990), "Orchestrating the human genome project", Science, v. 248, pp. 49-51.

17 DulbeCCO, R. (1986), "A turning point in cancer research: sequencing the human genome", Science, v. 231, pp. 1055-1056.

18 El Proyecto del Genoma Humano (1990), Ed. Generalitat Valenciana (Monografias del Consell Valencià de Cultura), Valencia.

19 KHouRY, M. J. (1997), "Genetic Epidemiology and the future of disease prevention and public health", Epidemiologic Reviews, v. 19, n. 1, pp. 175-180.

20 Varios Autores, Proyecto Genoma Humano: Ética (1991), Ed. Fundación Banco Bilbao Vizcaya, Bilbao.

21 RESCHER, N. (1983), "The ethical dimension of scientific research", en COLODNY, R. G. (ed), Beyond the Edge of Certainty. Essays in Contemporary Science and Philosophy, University Press of America, Lanham (MD), 1965 (reimp., 1983), pp. 261-276.

22 Rechsteiner, M. C. (1991), “The Human Genome Project: misguided science policy", Trends in Biochemical Sciences, v. 16, pp. 455-459.

23 MurRaY, T. H. (1991), "Ethical issues in human genome research", FASEB Journal, v. 5, pp. 55-60.

24 Holtzman, N. A. y ANDRews, L. B. (1997), "Ethical and legal issues in genetic epidemiology", Epidemiologic Reviews, v. 19, pp. 163-174.

25 SMITH, J. D. (1991), "Determinismo biológico y concepto de la responsabilidad social: La lección de Carry Buck", en Varios Autores, Proyecto Genoma Humano: Ética, Ed. Fundación Banco Bilbao Vizcaya, Bilbao, pp.169-179. 